\title{
Immunomodulating properties of dilute drugs in human monocyte/macrophages cell line THP-1 as a model of dose-response effects
}

\author{
Marta Marzotto, Elisabetta Moratti, Debora Olioso and Paolo Bellavite \\ University of Verona, Dept. of Pathology and Diagnostics, Verona, Italy
}

Background: Immuno-modulating properties are evoked by many highly diluted drugs and may be the base of complex systemic effects of the remedies in the organism. Monocyte/macrophages exert a pivotal role in innate immunity regulation and in inflammation. THP-1 cells have become one of most widely used cell lines to investigate the function and regulation of monocytes and macrophages. These cells resemble primary monocytes-macrophages isolated from donors in the vasculature, with the advantage of homogeneous genetic background that minimizes the degree of variability in the cell phenotype; this trait is particularly important when studying the biological function of chemicals with high dilutions [1]. Using this model we tested different doses/dilutions of homeopathic and allopathic drugs.

Methodology: The cell line THP-1 derived from the blood of a patient with acute monocytic leukemia, resemble primary monocytes and macrophages in morphology and differentiation property. The cell line was provided by DSMZ Culture Collection and cultured in RPMI medium (Lonza) added with 10\% (w/v) fetal bovine serum (FBS, Lonza) and $2 \mathrm{mM}$ ultraglutammine, at $37^{\circ} \mathrm{C}$ in controlled atmosphere $(5 \% \mathrm{CO} 2,95 \%$ air) and complete humidity. In all the experiments the cells were seeded in microplates (40000 per well) in RMPI with $2 \%$ fetal bovine serum and exposed to phorbol-12-myristate-13-acetate (PMA, $20 \mathrm{ng} / \mathrm{ml}$ ) for $48 \mathrm{~h}$. In this period, the THP-1 cells adhered to culture plates and differentiated into a macrophage phenotype with marked morphological changes (Figure 1). Concomitantly with the addition of immunoactive drugs, cells were activated with different doses of bacterial lipopolysaccharide (LPS, from 0 to $100 \mathrm{ng} / \mathrm{ml}$ ) and incubated for $24 \mathrm{~h}$.



Figure 1: Pics of THP-1 cell without (left) and with PMA treatment (right). 
Betamethasone (Bentelan $\left.{ }^{\circledR}\right)$ was diluted/succussed in sterile water and added to cells at concentrations ranging from 0.01 to $100 \mathrm{ng} / \mathrm{ml}$. Gelsemium sempervirens (2ch, $3 \mathrm{ch}, 4 \mathrm{ch}, 5 \mathrm{ch}$, $9 \mathrm{ch}$ and $30 \mathrm{ch}$ ) and the corresponding controls were freshly prepared in glass tubes starting from $30 \%$ ethanol solutions (provided by Laboratoires Boiron and prepared following the French Pharmacopoeia) by 100x dilution in pure water and agitated in automatic dynamizer (see detail in [2]). The drugs were kept in the LPS-activated cells for $24 \mathrm{~h}$. The dosage of pro-inflammatory (TNF-a, IL-6 and IL-1b) and anti-inflammatory (IL-10) cytokines was monitored by immune detection with ELISA assays (eBioscience) starting from the culture supernatants. The variation of viability and cell density were examined by WST assay and by quantification of total protein with Bradford assay on lysed cells, respectively. Repeated experiments were conducted in microplates, being careful to perform analogous manipulations to the drug dilutions and the corresponding controls. Statistical analysis was performed by paired T-test on the data from multiple replicates of single experiments $(\mathrm{n}=6)$.

Results and discussion: After stimulation with different doses of LPS, the responses of THP-1 cells can be monitored by specific interleukin dosage. The production of IL-1B (as proof) in response to different doses of LPS is shown in Figure 2. The cell model is very sensitive to the changes of activator amounts, increasing exponentially the quantity of cytokine produced. The same was observed for the other cytokines investigated. The experiments with the immunoactive drugs were performed in intermediate condition of activation, that looked adequate to observe both increase and inhibition effects.

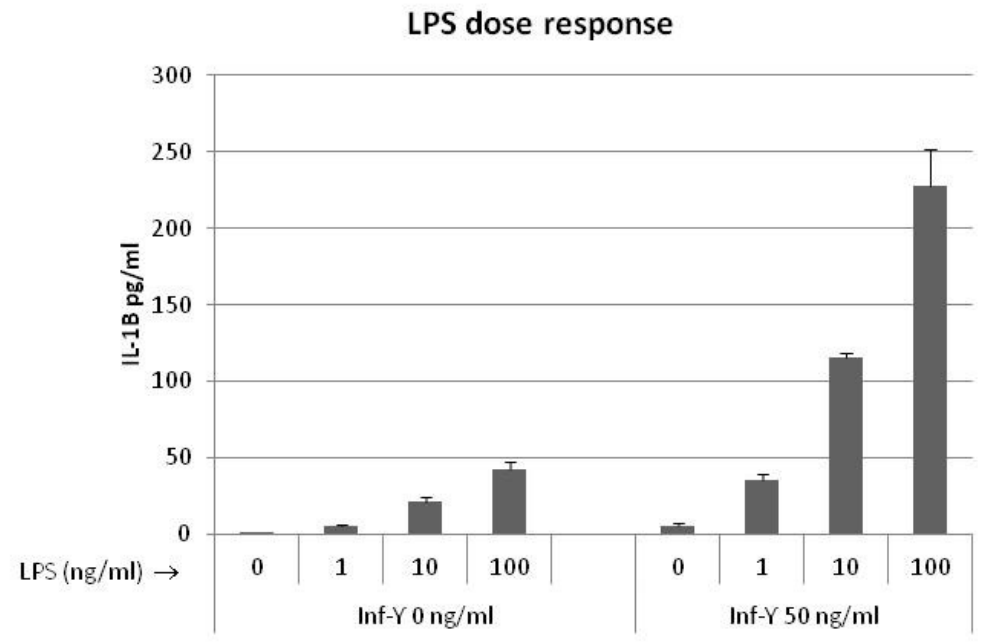

Figure 2. Quantification of the cytokine IL-1B produced in THP-1 cell supernatants after activation with increasing concentrations of LPS, in presence or not of interferon- $\gamma$ as co-activator. Histograms report mean values $\pm \mathrm{sd}$.

Betamethasone, a potent glucocorticoid steroid with anti-inflammatory and immunosuppressive properties, was used as model immunoactive drug. Figure 3 describes the effects of different doses of the steroid on LPSactivated cells. Notably, we tested the effect of "physiological" doses of blood circulating betamethasone and some of the doses that can be relevant in pharmacokinetics of the drugs (the therapeutic dosage in human correspond to the dose of $0.2 \mu \mathrm{M})$. As shown in Figure 3, the concentration of the proinflammatory cytokine TNF- $\alpha$ and IL-6 decreases linearly with the increase of the betamethasone dose, in particular when the cells were strongly stimulated with LPS $(100 \mathrm{ng} / \mathrm{ml})$. In contrast, if the LPS stimulus is weaker (LPS $10 \mathrm{ng} / \mathrm{ml})$ the direction of effect depends on the dose of betamethasone: low doses $(0.01$ and $0.1 \mu \mathrm{M})$ seem to increase the concentration of TNF-a, while larger doses exert a inhibitory action, as expected (Figure 3A). This effect can be described as a typical hormetic behavior and it was observed also left part of Figure 3C, where the IL-10 production is increased with low doses of the immunosuppressive drug. Notably, in the case of IL-10, the 
steroid did not impair significantly the cytokine production in THP-1 cells activated with LPS $100 \mathrm{ng} / \mathrm{ml}$. Actually, the activation pathway of the pro-inflammatory cytokine IL-10 is different from the TNF-a [3].

A.

TNF- $\alpha$

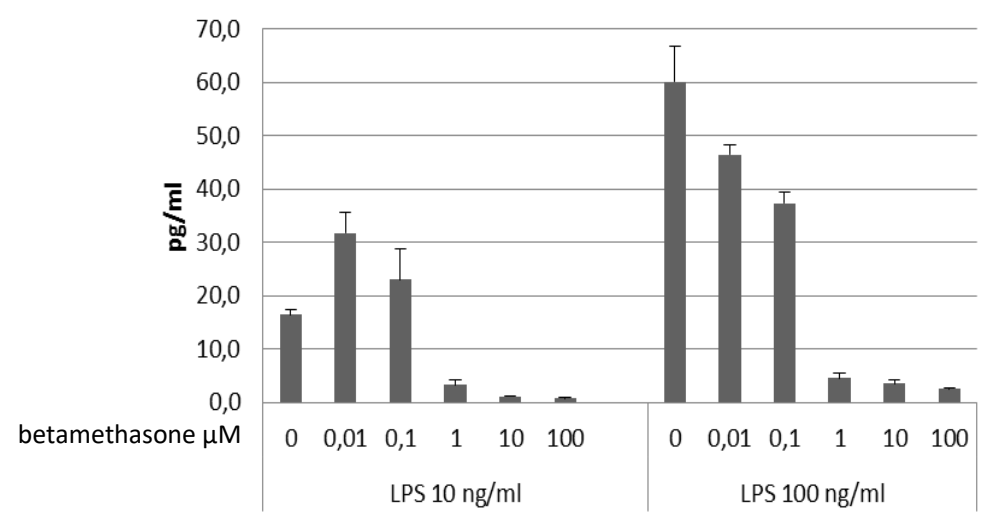

B.

IL-6

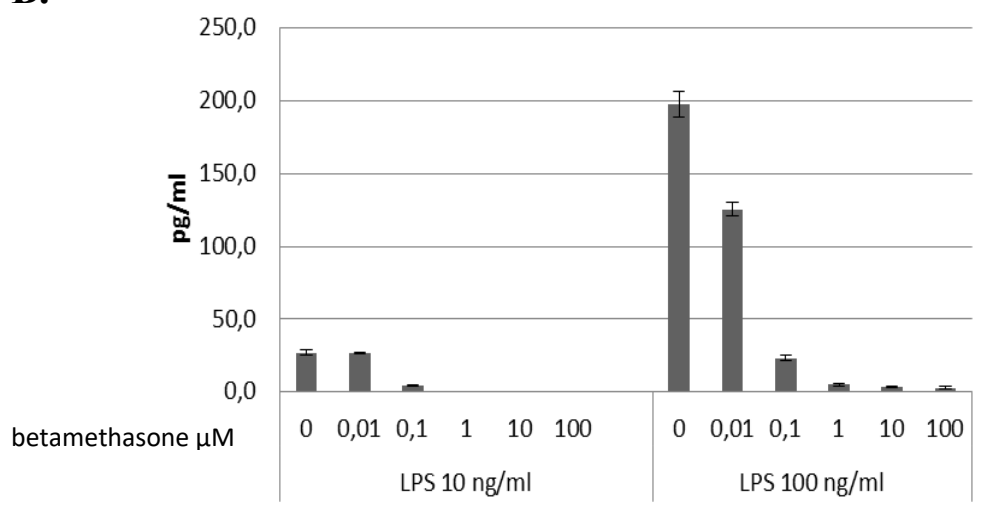

C.

IL-10

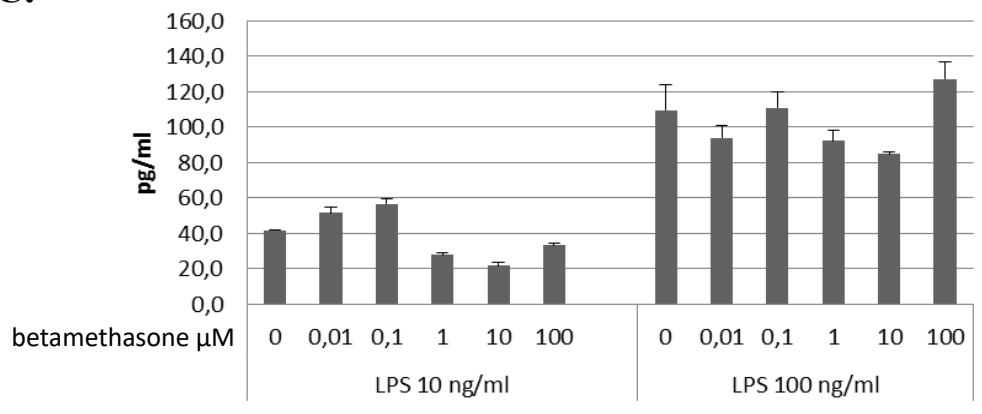

Figure 3. Effects of betamethasone on the production of the pro-inflammatory cytokines TNF- $\alpha$ and IL- 6 and the anti-inflammatory cytokine IL-10. The dose response experiments were performed both in presence of LPS 10 or $100 \mathrm{ng} / \mathrm{ml}$ as cell activators. Bars report mean value $\pm \mathrm{SEM}$.

The effects on THP-1 macrophages of Gelsemium sempervirens (2c, 3c, 4c, 5c, 9c and 30c) were compared with the corresponding potentized vehicles in cells activated with either high LPS dose $(100 \mathrm{ng} / \mathrm{ml})$ or low dose $(10$ $\mathrm{ng} / \mathrm{ml}$ ). Figure 4 shows the main results concerning three cytokines. This compound was tested both to extend our previous knowledge gathered with neuronal models [2] and because it is often used in influenza syndromes and in materia medica there are symptoms of fever and inflammation. 
A.

IL-6

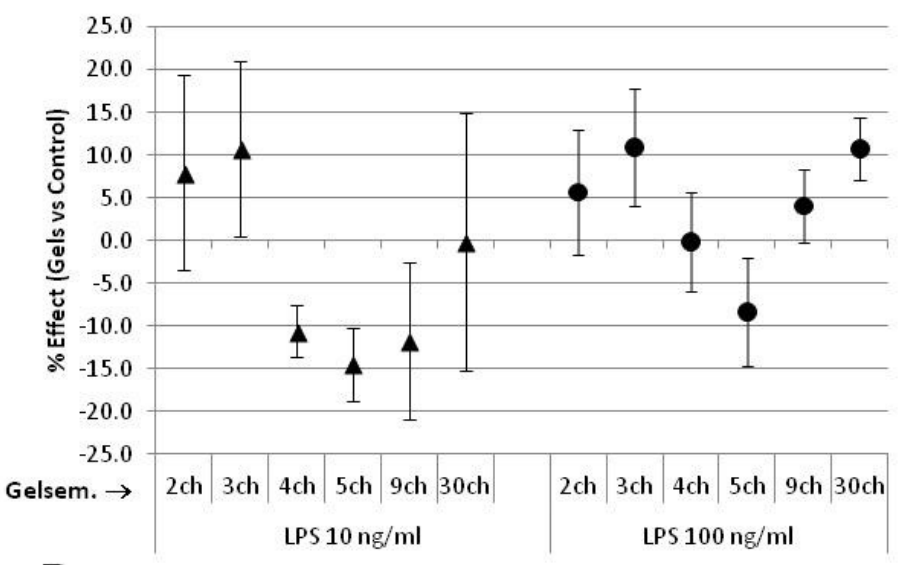

B.

TNF-a

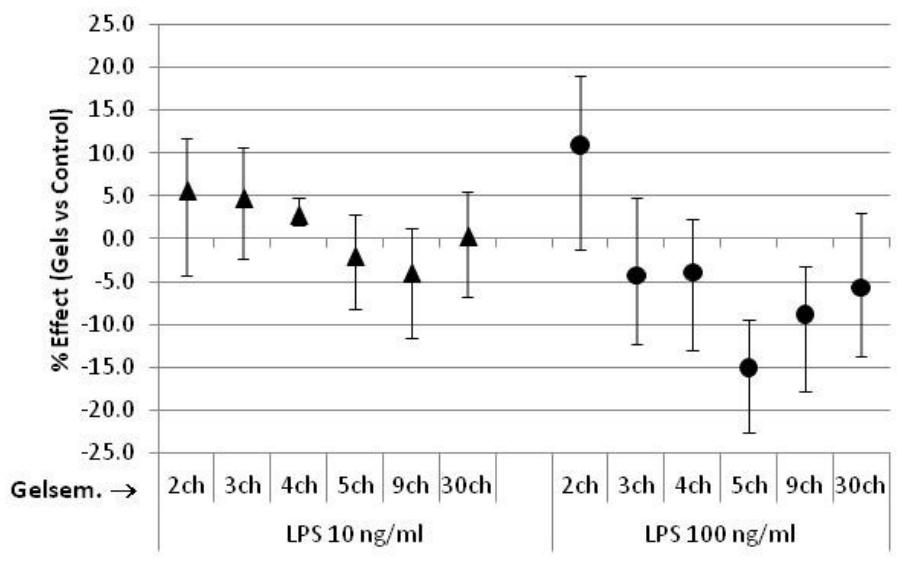

C.

IL-10

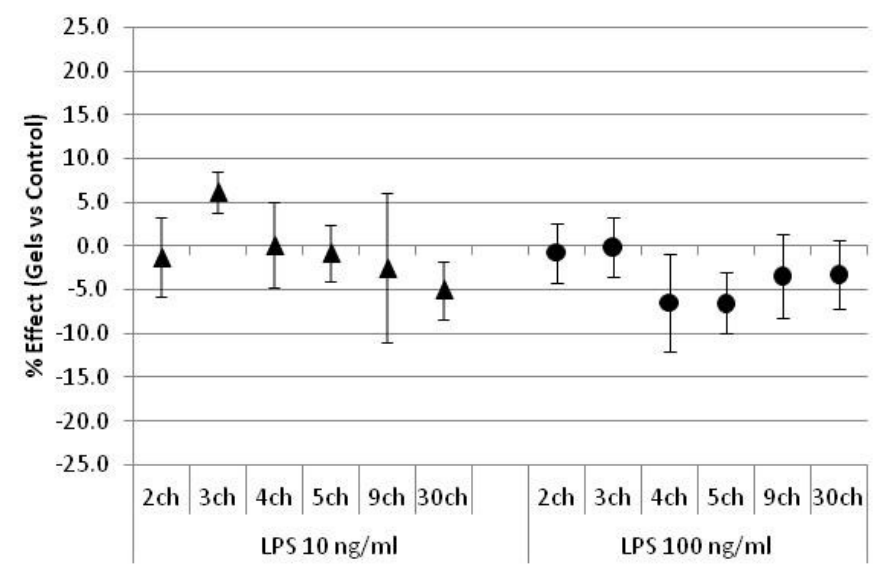

Figure 4. Percentage effect of Gelsemium s. treatment vs the corresponding succussed control at different dilutions on the THP-1 cytokine production. The variation of the cytokines concentration was measured in the supernatants of cells after $24 \mathrm{~h}$ of treatment by ELISA assay. Values in graphs are mean \% effect \pm SEM, $\mathrm{n}=12$, two replicated experiments.

As shown in Figure 4A and 4B, the pro-inflammatory cytokines IL-6 and TNF-a were apparently modulated by Gelsemium s., although not in a linear fashion with increasing concentration. Analogous trends were obtained in the two LPS conditions. The highest doses (low dilutions) increased slightly the cytokine production (Gels 2ch and 3ch), while a maximum of inhibition was observed with $4 \mathrm{c}$ and $5 \mathrm{c}$ dilutions. 
Statistical inference was obtained in the data from the separate experiments for the TNF-a inhibition with Gels $4 \mathrm{ch}(\mathrm{p}<0.05)$ and $5 \mathrm{ch}(\mathrm{p}<0.01)$. High variations hindered the statistical significance of IL-6 changes, which showed a similar trend. The changes observed in the anti-inflammatory IL-10 (Figure 4C) were not significant (around 5\% or less). The metabolic activity of the cells subjected to Gelsemium s. treatment was also analyzed at the end of the experiment by WST-assay (data not shown). Despite a tendency to inhibition of Gelsemium s. vs control, none significant variation was observed, with the exception of the small (-5.95\%) inhibition at $5 \mathrm{c}$ observed in the $10 \mathrm{ng} / \mathrm{ml}$-LPS-treated cells $(\mathrm{p}<0.05)$. The measure of cell density, as total protein content, has excluded the presence of significant differences of cells distribution among microwells and the absence of differential growth among samples (data not reported). THP-1 macrophages are a good model due to their sensitivity and the possibility to finely tune the activating conditions. Testing of further homeopathic products in this model is in program.

Acknowledgements: The research was supported by a grant from Boiron Laboratories (Lyon) and from the Italian Ministry of Research. The authors have no conflict of interest.

\section{References}

[1] Qin Z. The use of THP-1 cells as a model for mimicking the function and regulation of monocytes and macrophages in the vasculature. Atherosclerosis. 2012; 221(1):2-11.

[2] Marzotto M, Olioso D, Brizzi M, Tononi P, Cristofoletti M, Bellavite P. Extreme sensitivity of gene expression in human SH-SY5Y neurocytes to ultra-low doses of Gelsemium sempervirens. BMC Complement Altern Med. 2014; 14:104-.

[3] Barnes PJ. Corticosteroid effects on cell signalling. Eur Respir J. 2006; 27(2):413-26.

Keywords: THP-1 macrophages, LPS, betamethasone, Gelsemium s.

\section{(c)) EY-NC-ND Licensed to GIRI}

Support: Boiron Laboratories (Lyon) and Italian Ministry of Research

Conflict of interest: authors declare there is no conflict of interest

Received: March 30th 2014; Revised: May 10 th 2014; Published: June 30 2014.

Correspondence author: Marta Marzotto, marta.marzotto@univr.it

How to cite this article: Marzotto M, Moratti E, Olioso D, Bellavite P. Immunomodulating properties of dilute drugs in human monocyte/macrophages cell line THP-1 as a model of dose-response effects. Int J High Dilution Res [online]. 2014 [cited YYYY Month dd]; 13(47):100-104. Proceedings of the XXVIII GIRI Symposium; 2014 Jun 20-22; Sighisoara (Romania). GIRI; 2014; Available from: http://www.feg.unesp.br/ ojs/index.php/ijhdr/article/view/722/701 